\title{
Beyond the Search for Competition in Social Service Contracting
}

\section{Procurement, Consolidation, and Accountability}

\author{
Meeyoung Lamothe \\ Scott Lamothe \\ University of Oklahoma, Norman
}

\begin{abstract}
The authors argue it is time to move beyond thinking of competition in social service contracting simply in terms of whether competitive tendering procedures are used. Although the procurement process is important, other factors should be examined as well. In particular, they look at how market consolidation and accountability are related to competitive procurement. Findings indicate that demand side-driven consolidation (i.e., governments purposely choosing to go with fewer and larger contracts in which lead agencies manage vendor networks) has both competitive and noncompetitive aspects that are in need of further study and that the competition-accountability link is more complex than generally assumed. Although, as expected, there is evidence that competition, in and of itself, leads to some contractor turnover, it does not appear that competitive vendors are held to higher standards than their noncompetitive counterparts regarding performance (as measured by adherence to contract terms).
\end{abstract}

Keywords: competition; contracting; social services; accountability

$\mathrm{G}$ overnment privatizes, mostly in the form of contracting, for many reasons. Commonly cited rationales by policy makers and advocates include cost savings, efficiency, better service quality, flexibility, innovativeness, and limiting government growth (Kettl, 1993; Savas, 2000). What lies at the core of these assertions is, as Kettl (1993, p. 1) calls it, the "competition prescription." Greene (2002) affirms the notion by observing that, in general, "the evidence suggests that better efficiency comes from competition rather than from the privateness or publicness of organizations" (p. 49). Public choice theorists argue that both public and private monopolistic production of goods and services inherently leads to inefficiency (Ostrom \& Ostrom, 1971; Tullock, 1965). However, monopoly exists most notably in government. Privatization supporters thus contend that the injection of market-like competition into public service production, often through competitive procurement of goods and services from the private sector, will improve efficiency because competition forces potential bidders to be responsive to buyers' preferences and bid close to true production costs to win contracts (DeHoog, 1984).

In many service areas, especially at the state and local levels, the concept of competitive markets appears to be more rhetoric than reality (Van Slyke, 2003). In human service contracting, ${ }^{1}$ lack of competition is particularly evident; the literature suggests that lack or 
absence of competition in social service contracting is the norm rather than the exception (DeHoog, 1984, 1990; Donahue, 1989; Kettl, 1993; Kramer \& Grossman, 1987; Sclar, 2000; Smith \& Lipsky, 1993; Van Slyke, 2003). Despite the ample evidence of noncompetition provided in the existing literature, we argue that the previous findings and implications are severely limited, which raises two research questions. Given what we know from these past findings, can we convincingly say that noncompetition is the norm in social service contracting? More critically, is the competition-noncompetition dichotomy a realistic analytical framework for understanding the practice of contracting?

Addressing the first question, we argue that the previous scope of analysis has been too narrow. Most past examinations are heavily drawn from case studies and surveys in a few program areas of interest. Much of the contracting information was gathered at one time point or through subjective recollections or judgments made by survey respondents and interviewees. Our study examines a considerably wider array of health and human services-more than 6,000 contracts in 121 service areas such as mental health and substance abuse treatment and prevention, child protection and welfare, domestic violence and homeless shelters, adult services, developmental disabilities, and economic self-sufficiency. ${ }^{2}$ We also examine such data over a 5-year period rather than a single year "snapshot." Although our data are still limited because they originate from a single state, the generalizability of our findings should be superior to that of past research, which has been dominated by single-jurisdiction case studies involving a limited numbers of services. Furthermore, Florida's aggressive pursuit of outsourcing in the social services mirrors what many other states such as New York, Arizona, Michigan, and Kansas have experienced in recent years in terms of privatizing human service delivery.

Second, and more important, the implications of the previous findings are limited because the concept of competition has not been comprehensively and thoroughly explored-often the exclusive focus has been on whether the initial service purchasing process was competitive or not. Such a dichotomized characterization of the concept is problematic for the following reasons. Many contracts, in terms of how they are operated and managed, do not fall straight into this bifurcated mode of contracting patterns, but rather they run across a spectrum and contain both competitive and noncompetitive aspects. Likewise, the presumed benefits associated with competitive contracting modes, such as better efficiency and performance, often go unchallenged under this categorization. In this study, we substantially expand the scope of investigation on competition by exploring the potential complexity and multifaceted policy implications involving contracting practices. Particularly, we focus on investigating contract consolidation and the relationship between competition and accountability to shed light on this matter.

Contract consolidation, or a drop in the number of vendors used or available to bid on contracts, can occur for both supply- and demand-side reasons. It might be that the market is not able to sustain a critical mass of potential vendors after initial procurement because of vendor exit. But it is also possible that the government may purposively choose to limit the number of contractors with which it interacts . Demand-based consolidation is a recent phenomenon in which government bundles previously separate but interrelated service contracts into a few lead agency contracts. Once government awards a master contract to a lead agency, it is the lead agency's responsibility to secure and manage all subcontractors for integrated service delivery. As we elaborate on in later sections, this new contracting 
strategy does not quite fit into the existing conceptual bifurcation of competition versus noncompetition. On one hand, demand-side consolidation can be seen to promote competition in that the selection of lead agencies usually follows competitive procedures, often as a legal requirement. Rather than awarding and managing many, usually noncompetitively procured, small contracts, public managers now concentrate their resources and staff in securing and managing a few competitively bided lead agency contracts. Conversely, such consolidation could be a step back from competition because it usually relies on lengthy contractual commitments to a few large lead agencies, which raises the possibility of private monopoly or oligopoly in the future. It is not clear whether the benefits of this scheme outweigh the costs over the long term. Thus, we close with a call for future research and data collection into this up-and-coming and important development in contracting.

Further support for the idea of a competition continuum rather than a simple dichotomy is concerned with the competition-accountability link. A core question is, does competition promote accountability? More specifically, are competitively procured contractors held accountable more so than their noncompetitive counterparts? If we accept the competitionnoncompetition dichotomy based on market theory, the answers should be yes. But are they? Our findings suggest otherwise. Limited contract accountability is observed across the competitively and noncompetitively procured contracts. Regardless of the tendering mode, public managers appear to remove the poorest performers from their vendor pool, but they do not seem to hold competitive vendors to higher standards.

We begin our inquiry with descriptions of the data used. The theoretical and empirical exploration of competition in social service contracting follows. The focus of the discussions is on three aspects of competition: the prevalence of competitive procurement, whether there is evidence of consolidation of vendors and/or contracts over time, and the linkage between vendor performance and consequent contracting decisions. Implications of the findings and conclusions are provided at the end.

\section{Data}

We utilize five fiscal years (FY 2000-2001 through FY 2004-2005) of contracting information compiled by Florida's largest health and human services agency (Department of Children and Families [DCF]) to complete our analyses. DCF contracts with private entities for the majority of the services it provides. As of January 2006, the department had 1,116 contracts with a total value of \$3.69 billion (Florida Legislature Office of Program Policy Analysis and Government Accountability, 2006b).

The analyses are based on two sources of information: the Florida Accounting and Information Resource (FLAIR) and the Statewide Monitoring Reporting System (SMORES). The FLAIR database contains information regarding all health and human services contracts procured and managed by DCF. The types of data we obtain from this information system include contract managing district, vendor identity, contract amounts and periods, service types, procurement methods, and contract renewal status.

The SMORES database is the product of the DCF's recent effort to collect statewide contract compliance information by converting highly qualitative, district-based monitoring reports into quantitative measures with a 3-point rating scale (i.e., major, moderate, and 
minor) of contract noncompliance. ${ }^{3}$ Although this reporting system was never fully developed into an official database and was discontinued after 3 years of experiments, the final year of the pilot project (i.e., FY 2003-2004) provides data on contract compliance and performance that are comprehensive enough to be used for our analyses. ${ }^{4}$ A total of 205 on-site monitoring reports are utilized to examine vendor performance, which then is traced forward to the vendor's contract status (i.e., continued or discontinued) in the following year. The main focus of the oversight is on contract compliance including legal and program mandates, funding requirements, and contract-specific terms and conditions.

The total number of contracts examined in this article is 6,061 in 121 service areas under six different programs. Most contracts are negotiated and administered on an annual basis, although some are multiyear contracts. The most common contracting cycle begins with the first day of the fiscal year (July 1) and ends on the last day (June 30). However, contracts may have different decision cycles if their expiration dates are extended (up to 6 months) or their starting dates are delayed (e.g., October instead of July) for some reason. ${ }^{5}$ All health and human services contracts valued at less than $\$ 25,000$ are excluded from the data set because Florida law does not require these small contracts to be competitively bid. Many of these contracts are procured through standardized, statewide procedures for small purchases (Florida DCF, 2003a, 2005). ${ }^{6}$ All non-human services contracts, such as building maintenance and computer system development, are also excluded from the analyses. The majority of the vendors (about $77 \%$, on average, for the entire study period) were nonprofit organizations, with government agencies, for-profit business entities, and individuals composing the remainder. ${ }^{7}$ Subsequently, the discussions in the following sections mainly pertain to various contractual relationships and interactions between nonprofits as service providers and governments as buyers. Table 1 provides the detailed statistics about the programs under investigation with regard to the number of contracts and vendors and the contract amounts that are included in the analyses.

As can be seen, two program areas, family safety and mental health and substance abuse, dominated DCF contracting over the time frame of the study. Combined, these services accounted for $76.7 \%$ of all contracts and $95.6 \%$ of all contract dollars spent. Hence, our discussions and analyses will heavily focus on these program areas. In the following sections, we investigate the three aspects of competition (i.e., procurement, consolidation, and accountability) by first discussing the existing literature and then examining the Florida human service contracts data.

\section{Just How Prevalent is Competitive Procurement in Social Service Contracting?}

The extant literature commonly characterizes social service contracting as noncompetitive (DeHoog, 1984, 1990; Ferris \& Graddy, 1986; Kettl, 1993; Kramer \& Grossman, 1987; Smith \& Lipsky, 1993; Van Slyke, 2003). DeHoog (1984) finds from her case study of federally funded social and job training services that outsourcing human services involves much more complex processes and consequences than public choice theorists generally anticipate. She argues that competition and the resulting efficiency gains are seldom achieved in social service contracting because both governments as buyers and nonprofits 


\section{Table 1}

\section{Summary Description of Florida Human Service Contracting for FY 2000-2001 to FY 2004-2005}

\begin{tabular}{|c|c|c|c|c|c|c|}
\hline Program Area & $2000-2001$ & $2001-2002$ & $2002-2003$ & 2003-2004 & 2004-2005 & Change $(\%)^{\mathrm{a}}$ \\
\hline \multicolumn{7}{|l|}{ Family safety } \\
\hline Number of contracts & 520 & 507 & 541 & 401 & 213 & -59.0 \\
\hline Number of vendors & 294 & 288 & 299 & 232 & 146 & -50.3 \\
\hline Contract amounts (\$) & 390.8 & 370.1 & 428.9 & 641.7 & 687.4 & +75.9 \\
\hline \multicolumn{7}{|c|}{ Mental health and substance abuse } \\
\hline Number of contracts & 494 & 534 & 495 & 490 & 453 & -8.3 \\
\hline Number of vendors & 297 & 308 & 290 & 293 & 285 & -4.0 \\
\hline Contract amounts $(\$)$ & 559.8 & 571.6 & 575.9 & 568.3 & 558.9 & -0.2 \\
\hline \multicolumn{7}{|l|}{ Developmental services } \\
\hline Number of contracts & 250 & 224 & 219 & 109 & 90 & -64.0 \\
\hline Number of vendors & 156 & 138 & 130 & 77 & 73 & -53.2 \\
\hline Contract amounts $(\$)$ & 26.7 & 19.7 & 20.0 & 14.3 & 11.9 & -55.4 \\
\hline \multicolumn{7}{|l|}{ Economic self-sufficiency } \\
\hline Number of contracts & 38 & 87 & 101 & 80 & 81 & +113.2 \\
\hline Number of vendors & 32 & 64 & 67 & 52 & 52 & +62.5 \\
\hline Contract amounts (\$) & 44.6 & 17.2 & 19.8 & 13.9 & 13.0 & -70.9 \\
\hline \multicolumn{7}{|l|}{ Adult services } \\
\hline Number of contracts & 24 & 22 & 23 & 17 & 15 & -37.5 \\
\hline Number of vendors & 23 & 22 & 23 & 17 & 15 & -34.8 \\
\hline Contract amounts (\$) & 4.3 & 4.0 & 4.5 & 2.2 & 1.9 & -55.8 \\
\hline \multicolumn{7}{|l|}{ Health services } \\
\hline Number of contracts & 6 & 9 & 6 & 5 & 7 & +16.7 \\
\hline Number of vendors & 5 & 9 & 6 & 5 & 7 & +40.0 \\
\hline Contract amounts (\$) & 6.0 & 7.7 & 6.5 & 4.4 & 6.7 & +11.7 \\
\hline \multicolumn{7}{|l|}{ Total } \\
\hline Number of contracts & 1,332 & 1,383 & 1,385 & 1,102 & 859 & -35.5 \\
\hline Number of vendors & 807 & 829 & 814 & 676 & 578 & -28.4 \\
\hline Contract amounts (\$) & $1,032.2$ & 990.3 & $1,055.6$ & $1,244.8$ & $1,279.8$ & +24.0 \\
\hline
\end{tabular}

Note: Contract amounts are reported in millions of dollars. The numbers of contracts, vendors, and dollar amounts presented in this table are less than the Department of Children and Families (DCF) overall contract size because a number of contracts were excluded when they fell into the following categories: (a) all nonhuman services such as information technology, building maintenance, or personnel management; (b) all contracts whose contract amounts are $\$ 25,000$ or less for which a competitive procurement method is not required by policy or expected; (c) subsidized child care contracts (In FY 2000-2001, child care contracts constituted the biggest dollar amount contracts in the family safety program. The DCF went through divestiture in the following year by handing most of its large-scale child care contracts over to the Agency of Workforce Innovation as part of implementing the federal welfare reform policies. The DCF still has some child care training contracts, but they are much smaller in scale than before). Contract amounts were first annualized to obtain yearly expenditures (the presence of many multiyear contracts can greatly inflate the total contract amounts if not adjusted) and are presented in 2004 constant dollars.

a. Change $=(($ FY 2004-2005 - FY 2000-2001 $) \div$ FY 2000-2001 $) \times 100$.

as the main service deliverers have different incentive structures and engage in different decision-making processes from those involved in typical market transactions for hard goods and services. For instance, in social service contracting, cost savings are often less a 
priority than the quality and equity of service delivery and the achievement of client wellbeing (DeHoog, 1984). The contracting process can be more political than rational in that the executives, board members, and related advocacy groups of nonprofits become aggressive political forces that lobby to secure government funds for their causes and programs (DeHoog, 1984, 1990; Kettl, 1993; Smith \& Lipsky, 1993).

Van Slyke (2003) interviews New York state and county public managers in social service programs and finds inconsistent use of competitive bidding among the agencies. Barriers to competition exist both inside and outside of the government and include such concerns as the public agencies' lack of staff and resources to develop competition, anticipated market unavailability and the resultant unwillingness to utilize competitive bidding, and political pressure from lawmakers and elected officials who are lobbied by nonprofit executives and advocacy groups (Van Slyke, 2003). Meanwhile, Smith and Lipsky (1993, p. 173) point out the common presence of "mutual back-scratching" between nonprofits and government service agencies for advocating and developing programs. Social service agencies frequently perceive their nonprofit counterparts as goal-sharing partners who influence legislators and elected officials to make favorable decisions for their programs (Kettl, 1993). Moreover, nonprofit executives are often invited into public agencies' rule- or policy-making processes to provide input (Smith \& Lipsky, 1993).

A notable exception to this dominant theme of noncompetition in social service contracting is found in Savas (2002). He examines New York City's procurement process in three human service areas (homeless shelter, home care, and employment training) and observes significant competitiveness. The weakness of his findings is that although the government's intention to ensure competitive procedures (e.g., issuing bidding announcements, distributing requests for proposals [RFPs], etc.) is demonstrated, the actual number of proposals submitted by bidders is less than impressive (i.e., on average less than three per contract award). In addition, nearly all incumbent contract providers won the awards whenever they applied, and some of these vendors did not face any competitors in their bidding processes. We would argue that Savas, in effect, measures the use of best practices by government more so than actual competition. Hence, the general conclusion we take from the existing literature is that competition is often absent or at best substantially weak in social service privatization.

There are various explanations as to why noncompetition or a lack of competition is so prevalent in social service contracting. Both the history and the nature of human services seem to play roles. Historically, one of the main rationales for fostering nonprofit service delivery through government contracts and grants was promoting democracy rather than efficiency. The argument goes that such delivery arrangements enfranchise communitybased, neighborhood organizations and increase active citizen involvement (Kettl, 1993). Government's efforts to recruit service providers from nonprofit markets were often characterized as cooperative, invitational, and even nurturing rather than competitive (DeHoog, 1984; Kramer \& Grossman, 1987). As nonprofits established solid partnerships with government and government contracts became a primary funding source for many nonprofits (Salamon, 1987), these historical factors may have become less meaningful. However, the rapid growth in human service contracting during the past several decades has transformed many nonprofit enterprises into formidable political forces in social policy making (Kettl, 1993; Smith \& Lipsky, 1993; Van Slyke, 2003). DeHoog (1984, p. 27) characterizes this phenomenon as the "politics of cooptation" in which politically active contractors become 
close allies with government decision makers. Similarly, Van Slyke (2003) characterizes this as networking among nonprofits, public agencies, and elected officials.

The characteristics of health and human services are another factor that may contribute to the lack of competition. Many such services are by their nature difficult to measure in terms of specifying goals and evaluating provider performance (DeHoog, 1984; Donahue, 1989; Ferris \& Graddy, 1986). Although ensuring fair and effective competition requires substantial investment of staff time and resources to develop clearly specified RFPs (to include program goals, performance measures, program descriptions, staff qualifications, etc.) and to evaluate the bidders' proposals and past performance to identify the best one to meet the criteria (Kramer \& Grossman, 1987), such tasks can constitute a daunting challenge, even for public agencies with the requisite resources. Ironically, public managers often face severe resource constraints in fulfilling these tasks because of downsizing that typically accompanies privatization (Van Slyke, 2003). A common solution is to rely less on competitive bidding and more on relational contracting in which the agency and vendor engage in a more informal, cooperative, flexible, and interdependent relationship (Sclar, 2000, pp. 121-128; also see the related discussions in DeHoog, 1984). From the review of the existing literature, the indication of noncompetitive procurement appears to be ubiquitous, and we expect to witness similar patterns in Florida social service contracting. Our focus is to see whether and to what extent the largest Florida human service agency (DCF) utilizes competitive bidding processes to choose its vendors.

\section{Procurement of Florida Human Services}

The examination of the DCF's service procurement data indicates that noncompetition is indeed the dominant pattern observed in Florida human service purchasing. It is interesting that, however, the trend over the study period signals a rising level of competitive procurement in Florida. Table 2a demonstrates that the DCF contracts out most of its human services through noncompetitive procurement methods. In all five fiscal years reviewed, more than $80 \%$ of the contracts the agency executed and managed were not initially put out to bid. The most commonly used noncompetitive procurement method was the exempted category. These are services that are exempted by Florida Statutes from the requirements of competitive procurement. The FLAIR contracting information system recognizes 15 different types of statutorily exempted services (see the notes to Table 2a for details). The most frequently utilized exemptions are concerned with mental health services involving examinations, diagnosis, and treatment; services provided by nonprofits for the mentally or physically disabled; prevention services provided by nonprofits related to mental health including drug abuse and child abuse prevention; and contracts with other government agencies. For example, these four categories compose approximately $81 \%$ of all the exempted-by-law contracts in FY 2004-2005. Scholarly research as to why noncompetitive procurement has widely been used in Florida and still is one of the dominant purchasing modes for human services is nearly nonexistent. However, we consider several potential factors that might have contributed to the phenomenon.

First, under an earlier contracting system, Florida mainly adopted invitations to bid (ITB) as the standard method for competitively procuring goods and services. ${ }^{8}$ But many human 


\section{Table 2a \\ Procurement Methods Used in Social Service Contracting: Proportion of Contracts}

\begin{tabular}{lccccrr}
\hline & $\begin{array}{c}2000-2001 \\
(\%)\end{array}$ & $\begin{array}{c}2001-2002 \\
(\%)\end{array}$ & $\begin{array}{c}2002-2003 \\
(\%)\end{array}$ & $\begin{array}{c}2003-2004 \\
(\%)\end{array}$ & $\begin{array}{c}2004-2005 \\
(\%)\end{array}$ & $\begin{array}{c}\text { Overall } \\
\%\end{array}$ \\
\hline Noncompetitive: Exempted $^{\mathrm{a}}$ & 87.2 & 81.8 & 82.2 & 79.6 & 78.7 & 82.3 \\
Noncompetitive: Other $^{\mathrm{b}}$ & 3.3 & 2.4 & 1.6 & 1.8 & 4.1 & 2.5 \\
Competitive: Successful $^{\mathrm{c}}$ & 8.7 & 15.1 & 15.6 & 17.8 & 16.6 & 14.5 \\
Competitive: Unsuccessful $^{\mathrm{d}}$ & 0.8 & 0.7 & 0.7 & 0.8 & 0.6 & 0.7 \\
$n^{\mathrm{e}}$ & 1,332 & 1,381 & 1,375 & 1,083 & 831 & 6,002 \\
\hline
\end{tabular}

a. The "noncompetitive exempted" category includes services that were contracted out noncompetitively under the regulated exemptions referred to in chapter 287.057(5)(f), Florida Statute. These include contracts for individual artists' work; academic program reviews; health services involving examination, diagnosis, treatment, prevention, medical consultation, or administration; legal services including attorney, paralegal, and expert witnesses; Medicaid services; services to persons with mental or physical disabilities by nonprofit corporation exempted under sec. 501(c)(3) of the U.S. Internal Revenue Code; auditing services; family placement and adoption placement services licensed by the Department of Children and Families; prevention services related to mental health including drug abuse and child abuse prevention, and shelters for runaways, operated by nonprofit corporations; training and education services provided to injured employees; and lectures by individuals. b. The "noncompetitive other" category includes the services purchased through single sources, emergency purchases, the Department of Management Services Contractual Services State Contract System, the Another Government Agency Contract system, and small purchase procedures.

c. The "competitive successful" category is the services that were procured through such competitive solicitation processes as invitation to bid, request for proposal, or invitation to negotiate. This category also includes the services that were initially procured through the aforementioned methods and renewed.

d. The "competitive unsuccessful" category is concerned with the services that were competitively solicited but resulted in no response or only one response from potential bidders.

e. This table contains fewer contracts than those presented in Table 1 because of missing procurement information.

services, especially behavioral health care, were exempted from this practice because the quality of services and specific needs of clients were considered more important than simply finding the lowest cost vendor. Also, precisely defining the requested services, as required in an ITB, is difficult for these types of services. Second, during the 1960s and 1970s, needs and demands for community-based mental health centers operated through government contracting greatly increased as many states pursued deinstitutionalization strategies (i.e., shutting down state mental hospitals) in an effort to shift costs to the federal government through programs such as Medicaid (Torrey, 1997). Given the scarcity of available and qualified providers to deliver contracted client services at the time, states essentially nurtured new vendors, especially nonprofit entities, by building needed facilities, soliciting potential contractors, and technically assisting and training them to deliver contracts. Third, the private markets for social services have grown substantially since then, but it is hard to overcome institutional inertia, interdependency, and entrenched interests - the vendors have become more political and quite adept at lobbying the legislature to protect their interests. ${ }^{9}$

Over the entire study period, competitive procurement accounts for only a small fraction of the DCF contracting (less than 20\%). However, the proportion of the services that are competitively contracted out appears to be increasing over time (see Table 2a). For example, 


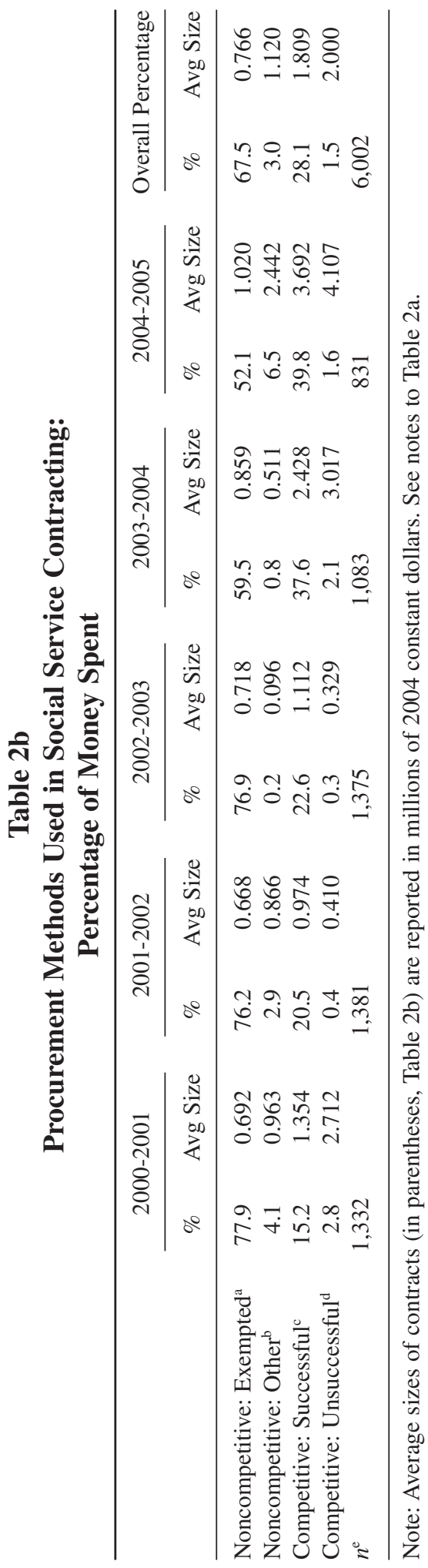


between FY 2000-2001 and FY 2004-2005, noncompetitive procurement (i.e., exempted and other) decreased by 7.7 percentage points, whereas successfully competitively procured contracts increased by 7.9 percentage points. ${ }^{10}$

Dissecting the data by contract amounts instead of the number of contracts more convincingly suggests that competitive procurement is on the rise in Florida social service contracting. Table $2 \mathrm{~b}$ shows substantial increases in the proportion of contract spending awarded through competitive processes over time. Competitively awarded contracts accounted for just $15.2 \%$ of spending in 2000-2001. But this proportion increased every year and reached nearly $40.0 \%$ by 2004-2005. Following from this, we see that "competitive: successful" contracts were consistently larger, on average, than their "noncompetitive: exempted" counterparts (examining the other categories - "noncompetitive: other" and "competitive: unsuccessful" - in this context is less useful as each represented few contracts each year [an average of 30 and 8 , respectively] and therefore were very vulnerable to changes in individual contracts).

What facilitated the enhancement of competitive bidding? The biggest reason is a legal mandate (see Florida Statues 287.057(1)(a)) for competitively soliciting contracts greater than $\$ 25,000$ except for those that are specifically exempted from the requirements. Among many newly outsourced and existing contracts, especially in the family safety program area, as discussed in detail in the following section, there has been a trend toward increasing size and scope, which subjects them to mandatory competitive procurement. We also partially credit the recent DCF reorganization for the change. The DCF undertook a major overhaul of its contracting system, starting in 1998, in efforts to specialize and professionalize its contract management functions. A full-time contracting unit was created in each district to effectively administer and manage district contracts. At DCF headquarters, the Office of Contracted Client Services was established to develop statewide policies on procurement, contract administration and operations, and contract monitoring. Although the aforementioned changes generally enhanced the agency's contract management capacity to handle more rigorous purchasing processes, specific features such as establishing contract proposal evaluation and negotiation teams and creating standardized contract templates enabled public managers to process large batches of competitively bided contracts in an efficient manner. Compared to contract management systems in many other states, we can say that Florida, especially the DCF, appears to have a highly centralized contract management structure. Also, it is worth pointing out that a market proponent—Jeb Bush—held the Florida governorship over the time frame of the study. Although many of the privatization efforts preceded Bush's arrival, he and his appointees are certainly enthusiasts who put much effort into continuing and accelerating market-oriented approaches and practices.

Related to all this, DCF changed the way it handles its family safety contracts, which dramatically altered the nature and scope of these contracts. For example, between FY 2000-2001 and FY 2004-2005, the proportion of family safety contracts that were competitively tendered increased from $7.5 \%$ to $21.9 \%$, and the proportion of contracting dollars in this program spent on competitively procured contracts increased from $21.3 \%$ to nearly $63.0 \%$. By contrast, the mental health and substance abuse program (remember, these two programs account for about $96 \%$ of all the spending in our data) saw more moderate increases. The percentage of competitively awarded contracts moved from $9.3 \%$ up to $12.2 \%$, and spending rose from $9.7 \%$ to $12.2 \%$. These changes are discussed below. 


\section{Competition or Consolidation in Social Service Markets?}

The second aspect of competition we explore, consolidation, has received little empirical attention, although its theoretical implications have been abundantly discussed in the social service contracting literature. It should be noted that we limit our investigation of this concept to the consolidation of the contracts and vendors generally, but not individual service providers per se, because of the lack of data availability. That is, we are not able to specifically test if vendors gather increasing market shares over time but rather simply if there are diminishing numbers of contracts and/or vendors across the time frame of the study.

Consolidation occurs when governments come to rely on a few large-scale providers for integrated programs rather than negotiating individual service contracts with small community-based organizations. Consolidating or bundling individual services into larger and fewer contracts may weaken competition by eventually reducing the number of available vendors in the social service markets. According to this logic, small, local providers who do not have financial and programmatic capacities and flexibilities are not as competitive as large, multiprogram providers in ensuring contract awards and thus are more likely to lose program funding from government as it promotes consolidation. As a consequence, small vendors will eventually be pushed out of the market. If this occurs, governments may become more dependent on large providers for service delivery. Such limited markets might hinder governments' abilities to leverage what they can buy and could promote opportunistic behavior by vendors. This, in turn, could result in increased transaction costs for governments because monitoring and accountability are harder to manage when competition is limited (DeHoog, 1984; Williamson, 1985).

Despite this possibility, however, incentives to consolidate seem to exist both within governments and among nonprofit organizations. Some nonprofits aggressively seek to expand their programs to become "miniconglomerates" (Kramer \& Grossman, 1987, p. 44) in hopes of maximizing government funding opportunities. Kramer and Grossman (1987) note that such trends frequently reflect "changing governmental funding priorities, the (nonprofit) agency's funding strategy, and its entrepreneurial skills" (p. 44). Simply put, organizations that can adapt to changing environments by offering services in a variety of areas are less likely to suffer fiscal distress; hence, expansion can be seen as a way of promoting stability.

From the government's point of view, there are several reasons why public managers might prefer large providers to small grassroots organizations. First of all, they may have incentives to do so to reduce transaction costs associated with procuring, negotiating, writing, executing, and monitoring individual contracts because consolidation means managing fewer contractors. Another force that may promote consolidation in social service contracting is an increasing emphasis on nonprofit accountability (Kearns, 1994; Keating \& Frumkin, 2003; Stone, Bigelow, \& Crittenden, 1999). With rising concerns about nonprofit performance and contract compliance in carrying out public services, government tends to favor bigger and more business-like providers with better financial and administrative capacities. Small, grassroots, community-based organizations often lack sufficient internal controls, client databases, reporting systems, and professional staff (Kramer, 1994; Smith \& Lipsky, 1993). Last, government may seek to improve efficiencies by contracting with vendors with large production capacities and take advantages of economies of scale (Ferris \& Graddy, 1986). 
A question is then how the DCF weighs the relative magnitudes of these costs and benefits in its decision making. The obvious and immediate benefits associated with consolidating contracts could likely overwhelm concerns of increases in transaction costs in the future as the possibility of monopolistic contracting environments may seem remote and inconsequential to government officials who tend to have limited time horizons.

By analyzing longitudinal information on Florida social services contracts, we scrutinize whether consolidation (i.e., reductions in the number of contracts and/or vendors while funding levels remain stable or rise) has occurred. We then move to a closer examination of a program area that appears to show evidence of consolidation and discuss its policy implications.

\section{Consolidation in Florida Social Service Contracting}

The examination of the Florida social service contracting patterns provides mixed evidence on consolidation. As Table 1 exhibits, mental health and substance abuse services, one of the two biggest program areas, display minor fluctuations in terms of the number of contracts and vendors over the time frame of the study (i.e., the number of contracts and vendors drop by $8.3 \%$ and $4.0 \%$, respectively). The total contract dollars for these services reflects this stability because it shows essentially no change over time (i.e., a $0.2 \%$ drop between FY 2000-2001 and FY 2004-2005). Other programs such as adult and developmental services show diminishing numbers of contracts and vendors. An administrator explained to us that, during this period, DCF transferred the developmental services program to the Agency for Persons with Disabilities, which tracks its contractual services through a different database. So although DCF still provides administrative functions, including contract administration, to this program, much of the budget moved off the FLAIR database used in our analysis. Similar changes occurred regarding adult services. A slightly different pattern is observed in economic self-sufficiency services in that there was a substantial increase in the number of contracts and vendors between the FY 2000-2001 and FY 2001-2002, mainly because of newly added homeless services. ${ }^{11}$ None of these changes, however, meet our definition of consolidation.

On the other hand, a glance at the contracting patterns in the family safety program signals the potential occurrence of consolidation (see Table 1). The number of family safety contracts and vendors dropped by fairly sizable amounts (59.0\% and 50.3\%, respectively), whereas expenditures increased notably (75.9\%), indicating that changes were not related to less contracting effort or funding shifts by the state. If these statistics suggest potential evidence of consolidation, the next question is, why has it occurred in the family safety program in particular, and what has really happened?

A closer look at the family safety program data suggests that the majority of the changes reflect what has taken place in recent years in child welfare services. The transformation involves both integrating conventional out-of-home care service contracts into single, large, community-based care (CBC) contracts and further privatization of the remaining public child welfare services and related management functions to lead agencies. ${ }^{12}$ Our study period (FYs 2001 to 2005) captures almost the entire process of this transformation because the DCF executed its first CBC service contracts in FY 2000-2001 and completed its 
Table 3

Consolidation in the Family Safety Program

\begin{tabular}{lrrrrr}
\hline & $2000-2001$ & $2001-2002$ & $2002-2003$ & $2003-2004$ & $2004-2005$ \\
\hline Number of contracts & & & & & \\
$\quad$ Non-CBC & 516 & 501 & 534 & 383 & 189 \\
CBC & 4 & 6 & 7 & 18 & 24 \\
$\quad$ Total family safety & 520 & 507 & 541 & 401 & 213 \\
Number of vendors & & & & & \\
$\quad$ Non-CBC & 290 & 283 & 292 & 214 & 124 \\
CBC & 4 & 5 & 7 & 18 & 22 \\
$\quad$ Total family safety & 294 & 288 & 299 & 232 & 146 \\
Contract amounts & & & & & \\
$\quad$ Non-CBC (\$) & 347.9 & 271.9 & 309.0 & 257.9 & 194.6 \\
CBC $(\$)$ & 42.8 & 98.1 & 119.9 & 383.8 & 492.9 \\
$\quad$ Total family safety $(\$)$ & 390.8 & 370.1 & 428.9 & 641.7 & 687.4 \\
\hline
\end{tabular}

Note: $\mathrm{CBC}=$ community-based care.

statewide transition to the CBC contract structure in FY 2005-2006 (Florida Legislature, Office of Program Policy Analysis and Government Accountability, 2006b). ${ }^{13}$ As of January 2006, the DCF had 22 CBC service contracts worth \$625.4 million with 20 lead agencies to provide child protective services in all of the state's 67 counties (Florida Legislature, Office of Program Policy Analysis and Government Accountability, 2006a). Table 3 illustrates how the sizable reductions in the contracts and vendors and simultaneous increases in the contract funding levels over time correspond with the emergence of the CBC contracts in the family safety program.

The core idea of the CBC or more generally the "lead agency" model (McCullough \& Schmitt, 2000) is to establish integrated systems of care to provide comprehensive and coordinated child protective services (e.g., family preservation, emergency shelter, foster care, and adoption services) to all children and families residing in a community (Falconer, Cash, \& Ryan, 2001). A lead agency acts as a managed care entity that develops and manages a network of service providers (McCullough \& Schmitt, 2000) and assumes the majority of program planning, coordination, and management functions that public agencies previously carried out. The underlying rationales and expectations are to curb rapidly rising costs and workload and to improve efficiency and the quality of care in troubled child welfare systems (Field, 1996) by borrowing the concept of "managed care principles and practices from health and behavioral health care fields" (Courtney, 2000, p. 88).

The CBC transformation in Florida reflects a wider child welfare reform initiative based on this managed care approach. Although some critics view this new managed child welfare innovation as another "vehicle for the privatization of public child welfare services" (Embry, Buddenhagen, \& Bolles, 2000, p. 94), Florida eagerly adopted the initiative and began to restructure its child welfare service delivery system by statutorily mandating the DCF to enter into contracts with lead agencies in 1998 (Florida Legislature, Office of Program Policy Analysis and Government Accountability, 2004). Florida is not alone in its desire to transform its child protective services through a managed care approach. McCullough and Schmitt (2000) report that 29 states had undertaken such initiatives as of 
1999, with more than half adopting a lead agency model similar to Florida's in which there is some risk sharing between the contracting entity and the vendors. In an update based on 2001 data, McCullough and Schmitt (2003, pp. 64-70) found that four additional states had managed care initiatives, indicating that the movement continues to diffuse through the states. Thus, the Florida experience speaks to a larger movement that affects much of the country.

Risk sharing or risk transferring is a particularly attractive aspect of the CBC model. Under this approach, contract amounts are usually capitated, and lead agencies are obligated to provide wraparound services (e.g., foster care, case management, placement, adoption, etc.) to all eligible children in their jurisdictions, which typically cover one or more counties. Lead agencies, therefore, have clear incentives to be efficient in allocating resources and managing cases. Another merit of the CBC model is its use of clear outcome measures as a way to ensure contract accountability. Although most Florida client service contracts are considered performance contracts, typical measures included in contracts are often beyond what individual providers can achieve within annual contracting cycles, which makes it almost impossible to hold vendors accountable for their outcomes. In addition, gathering performance data is often not part of provider reporting requirements. By contrast, CBC contracts are built around clearly written and measurable outcomes that can be traced back to lead agencies' performance. Data gathering on performance measures is systematic rather than haphazard.

Although Florida has chosen consolidation rather than market competition as a way to achieve effective service delivery, the question remains as to whether this demand-side initiative will eventually lead to monopolistic or oligopolistic markets and, if it does, whether the benefits from a consolidated market will still prevail. Any attempts to answer this question here are inappropriate because the subject is beyond the scope and analysis of our study. However, there are some important clues that are currently observable in the search for answers. First of all, the DCF has increasingly utilized multiyear commitments for the consolidated CBC contracts, which could significantly facilitate monopolized markets. Although the agency shows an increasing preference for longer-term contracts across all program areas (93\% of all contracts executed in FY 2000-2001 were annually based, whereas only $81 \%$ of the total contracts were so in FY 2004-2005), the trend is particularly marked regarding the large and expensive CBC contracts. ${ }^{14}$ The average contract length and annualized amounts of the CBC contracts for FY 2004-2005 are 3.4 years and \$20.5 million, respectively, compared to 1.3 years and $\$ 953,600$ for all non-CBC contracts. Long-term contracts could be considered anticompetitive in that they limit the effectiveness of accountability mechanisms over the term of the contract (contract termination requires greater malfeasance than nonrenewal) and likely diminishes the pool of competitors by denying them access to government funding for protracted periods. ${ }^{15}$

On the other hand, other forces exist to mitigate the potential for the seeking of monopoly rents. Although the magnitudes, longevities, and complexities of consolidated contracts clearly provide the incumbent $\mathrm{CBC}$ lead agencies with advantageous negotiation power, they have less control and leverage than one might expect in their contractual relationships with the government. One of the reasons for this is that lead agencies are often responsible only for managing and coordinating subcontractors who deliver the actual services. The lead agencies' dependence on the networks of subcontractors is evidenced by the fact that 
as of December 2005, there were 20 lead agencies throughout Florida managing 500 subcontracts, including 64 subcontracts with case management organizations (Florida Legislature, Office of Program Policy Analysis and Government Accountability, 2006a). Any move by government to change management in the case of poor lead agency performance could disrupt service continuity but is certainly "doable" without causing a sudden collapse of existing service delivery structures because, by and large, the managers are not participating in direct service delivery (and if they are, it is possible that they could lose the management contract while retaining delivery duties). In fact, two incumbent lead agencies lost their contracts in 2004 mostly because of financial problems (Florida Legislature, Office of Program Policy Analysis and Government Accountability, 2006a), but the transitions to new lead agencies were done without leaving their respective districts in chaos. Therefore, it may be that CBCs can be seen as striking a balance between the potential dangers of consolidation and the advantages of fairly stable community-based networks. This would be in line with the view of some scholars that public managers often act more as pragmatists than as ideologues when designing their service delivery systems (see Hill \& Hupe, 2002, 109; Warner \& Hefetz, 2004).

\section{Are Social Service Providers Held Accountable Through Competition?}

The final aspect of competition we examine is concerned with contract monitoring and whether contractors are held accountable for their performance. In spot markets, true market accountability occurs-good performers are rewarded through the sales of their products, and poor performers exit because they are unable to earn profits. No organized oversight is required. This is not the case with contracting for services. The contracting government must actively monitor vendors to ensure performance is acceptable. As DeHoog (1984, p. 21) states, "An effective government watchdog role" is one of the critical conditions for successful contracting under market-like competition. This leads us to believe that there are two forms of accountability that must be examined.

The first, which we term the internal managerial control component, relates to efforts by the government to judge vendor performance and maintain compliance. Most obvious, this entails the monitoring of the contractors over the terms of the contracts. Vendors who are deemed to not be meeting their contractual obligations should be identified through the monitoring process and should be sanctioned accordingly (e.g., have their contracts pulled or not renewed) regardless of the tendering method (i.e., competitive or noncompetitive). But there is also a market component that, in some ways, may enhance the internal control. We develop two hypotheses regarding market accountability. First, the competition hypothesis posits that competition, independent of performance, should be associated with vendor turnover because, at least on occasion, good vendors should lose contracts to high-quality competitors. In addition, we expect that monitoring matters more for competitive vendors because agencies should be more willing, and possibly find it easier, to replace marginally performing vendors when the contracting environment is competitive in nature. Problems that might not warrant action against noncompetitive contractors might be enough to lead to action being taken against competitive vendors. This we name the differential impact 
hypothesis. Specifically, contractors who earned their contracts through competitive processes should be more likely to suffer performance-related sanctions (i.e., losing contracts) than their noncompetitive counterparts.

With regard to the types of performance criteria, Romzek and Dubnick (1994) provide four dimensions that should be considered as determinants of future contracting decisions: hierarchical, legal, political, and professional accountabilities. In social service contracting schemes, commonly adopted accountability measures are legal in nature (Dicke \& Ott, 1999) and involve broad sets of external control mechanisms on process including laws, mandates, program standards, regulations, and other contractual terms and conditions (Bardach \& Lesser, 1996; Blasi, 2002; Dicke, 2002; Dicke \& Ott, 1999; Romzek \& Johnston, 2005). Contract oversight in DCF is often focused on these legal and contractual aspects because they are relatively easy to measure and enforceable in the form of written contract clauses (Lamothe, 2004). Our effort to tie provider accountability to future contracting decisions, therefore, focuses on vendor compliance with legal and contractual terms and conditions. More specifically, we examine the following aspects as defined in the SMORES: invoicing, service tasks including legal and program mandates, personnel and staffing, performance specifications, incident-reporting procedures, and administrative monitoring related to federal and state rules and regulations.

\section{Accountability Through Competition and Monitoring in Florida}

To examine the effects of both managerial control through the oversight of provider performance and competition on contracting, we focus our analysis on three variables. The first, used to measure contractor performance, is the number of major violations reported for the contractor in the SMORES database. Contract noncompliance is rated as "major" if failures could result in harm to clients or interruption of service or if there is evidence of fraud or severe fiscal instability in the provider (Florida DCF, 2003b). ${ }^{16}$ The managerial control hypothesis posits that, regardless of the nature of the initial tendering, the number of major violations will have a negative impact on the likelihood of contract continuation as these problems can be detrimental to achieving contract effectiveness.

The second focus variable is the proportion of the vendor's contracts that were competitively procured. Ceteris paribus, the competition hypothesis postulates that contractors operating in more competitive environments (i.e., services involving competitive procurement) should be less likely to maintain contracts because replacement vendors should be easier to come by. ${ }^{17}$ The third, and final, variable of interest is an interaction term produced by multiplying the performance and competition variables together. This measure allows us to test if the impact of poor performance (as measured by the number of major violations) is conditioned by the contracting environment (i.e., competitive or noncompetitive). If this differential impact hypothesis holds, we should see evidence that the influence of major violations is greater on vendors with larger percentages of competitively procured contracts. Hence, we expect the estimate on this variable to be negative and significant.

We link SMORES data from FY 2003-2004 to contract status in FY 2004-2005 to test the above hypotheses. Ideally, we would like to use individual contracts as the unit of analysis. 
Unfortunately, the monitoring reports contained in SMORES are for vendors, many of whom hold multiple contracts within a district. ${ }^{18}$ This, combined with the fact that many adverse findings are associated with vendor shortcomings and are not contract specific (e.g., fiscal instability), indicates that individual vendors in districts is an appropriate unit of analysis. ${ }^{19}$ We test our hypotheses using two dependent variables: whether the vendor maintained any contracts in the district in 2004-2005 and the number of contracts held in 2004-2005 relative to the number held in 2003-2004..$^{20}$

We also control for other potential influences on the likelihood of retaining contracts. Because our first dependent variable measures if any contracts are maintained, we control for the total number of contracts held in FY 2003-2004. Obviously, vendors with many contracts should be less likely to lose all than vendors with only one. The total dollar value of contracts held by vendors is also included. This measure taps into a similar dynamic as the number of contracts-large, influential vendors might be more difficult to replace. Although the connection between these two variables and our second dependent variable, proportion of contracts retained, may not be as obvious, reasons for the controls are similar. That is, ceteris paribus, vendors holding larger number of contracts will be likely to retain higher proportions of their contracts because public managers would usually prefer the status quo, which minimizes administrative and monitoring-related transaction costs, over new contracts with new vendors that involve new learning curves (Milward \& Provan, 2000). Similarly, vendors that attract large amounts of contracting dollars should tend to retain higher proportions of their contracts because they are more influential players in the contracting world and thus harder to replace. On the other hand, there is the possibility that vendors with more contracts will lose some simply because of an overall movement favoring contract consolidation. Looking back to Table 1, we see there is a general trend toward fewer contracts statewide over the time frame of our study (e.g., total contracts fell from 1,102 in 2003-2004 to 859 in 2004-2005), whereas spending increased. As there was not a drop in contracting effort, as reviewed previously, contract consolidation appears to have occurred. It is possible that vendors do not lose contracts because of poor performance, but rather the contracts they held are merged, resulting in fewer numbers of contracts, but not lower contract responsibility. These possibilities need to be controlled for.

As mentioned above, CBC in family safety is a statewide effort to coordinate service delivery that has led to much contract consolidation. Such consolidation is systematic and needs to be accounted for in our analysis because vendors could lose contracts for no other reason than new or expanded $\mathrm{CBC}$ activity occurred in their district. The potential impacts of contract consolidation on the likelihood of losing or retaining contracts in the next cycle is already partially captured in the control variable described above, the total number of contracts held. However, this CBC factor should be separately accounted for because there is a clear and direct link between the creation of new CBC lead agencies and the considerable reduction in the number of family safety contracts whose programs and services are overlapped with the CBC contracts. Finally, we take into account market condition. As other studies have suggested (Brown \& Potoski, 2003; Greene, 1996), larger, wealthier areas might provide a greater pool of prospective vendors, leading to more competition and a better contracting environment. We account for this possibility by controlling for district population density and per capita personal income. 


\section{Table 4}

Logit Analysis for Likelihood of Vendors Losing Any Contracts

\begin{tabular}{|c|c|c|c|c|}
\hline Variable & $b$ & $S E$ & $p$ value & Impact \\
\hline \multicolumn{5}{|l|}{ Performance and competition measures } \\
\hline \# of major findings & -0.100 & 0.052 & .054 & -.017 \\
\hline Proportion of contracts competitively procured & -1.804 & 0.742 & .015 & -.028 \\
\hline Major $\times$ proportion competitively procured & 0.513 & 0.385 & .182 & \\
\hline \multicolumn{5}{|l|}{ Controls } \\
\hline \# of contracts in $2003-2004$ & 0.413 & 0.225 & .067 & .051 \\
\hline Total value of contracts & 0.084 & 0.085 & .324 & \\
\hline New or expanded community-based care in 2004-2005 & -0.472 & 0.528 & .371 & \\
\hline District per capita personal income & 0.074 & 0.049 & .132 & \\
\hline District population density & 0.002 & 0.001 & .024 & .063 \\
\hline Constant & -1.994 & 1.424 & .162 & \\
\hline$n$ & \multicolumn{4}{|c|}{205} \\
\hline$\chi^{2}$ & \multicolumn{4}{|c|}{$41.436^{\mathrm{a}}$} \\
\hline$p$ & \multicolumn{4}{|c|}{.000} \\
\hline
\end{tabular}

Source: Statewide Monitoring Reporting System was the source for \# of major findings; Florida Accounting and Information Resource was the source for proportion of contracts competitively procured, \# of contracts in 2003-2004, total value of contracts, and new or expanded community-based care in 2004-2005; University of Florida (2005) was the source for the district per capita personal income and density measures.

Note: Impact is calculated for variables that reached at least marginal significance (i.e., $p<.10$, two-tailed) by increasing the value of these variables from their means to one standard deviation above their means while holding all other variables at their means or modes, as appropriate (the values for the multiplicative term were determined by the values of the base terms). The baseline probability of holding contracts (i.e., the probability when all variables are held at their means or modes, as appropriate) is .882 .

In Table 4, which shows the results for the model predicting vendor exit from the market, we find some support for our hypotheses and some interesting contradictions. The results indicate that provider performance, as measured by the number of major violations, is negatively associated with contract continuance for vendors who obtained their contracts noncompetitively $(b=-0.100, p=.054)$. Holding all other variables constant, a one standard deviation increase from the mean for this variable (i.e., moving from 1.86 to 6.56 "majors") decreases the probability of holding contracts by 1.7 percentage points. Although a change in probability of 1.7 percentage points might seem less than consequential to some, it is significant to point out that the baseline probability of retaining contracts (i.e., the probability when all variables are held at their means or modes as appropriate) is $88.2 \%$. Hence, the data are rather skewed. Because logit assumes maximum effects at a $50 \%$ probability of occurrence, predicted impacts are somewhat attenuated by the model at high baseline probabilities. Also, it is important to remember that a zero on the dependent variable indicates a loss of all contracts, which is a rather strenuous sanction. We interpret this variable to indicate that managers, through the monitoring process, are gathering the data they need to identify and sanction poorly performing vendors.

We also see that vendors with higher proportions of competitively procured contracts, but no major violations, are less likely to maintain their contracts $(b=-1.804, p=.015)$. In this case, a one standard deviation increase from the mean leads to a 2.8 percentage point 
Table 5

Regression Analysis of Why Vendors Lose or Gain Contracts

\begin{tabular}{lccc}
\hline Variable & $b$ & $S E$ & $p$ value \\
\hline Performance and competition measures & & & \\
$\quad$ \# of major findings & -0.013 & 0.007 & .073 \\
$\quad$ Proportion of contracts competitively procured & -0.413 & 0.134 & .002 \\
$\quad$ Major $\times$ proportion competitively procured & 0.039 & 0.056 & .487 \\
Controls & & & \\
$\quad$ \# of contracts in 2003-2004 & -0.045 & 0.022 & .048 \\
$\quad$ Total value of contracts & 0.003 & 0.006 & .562 \\
$\quad$ New or expanded community-based care in 2004-2005 & -0.085 & 0.087 & .327 \\
District per capita personal income & 0.016 & 0.007 & .016 \\
$\quad$ District population density & 0.000 & 0.000 & .034 \\
Constant & 0.300 & 0.202 & .140 \\
$n$ & & 205 & \\
$F$ & & 6.256 & \\
$p$ & & .000 & \\
Adjusted $R^{2}$ & & .171 & \\
\hline
\end{tabular}

Note: $p$ values are based on two-tailed tests. See notes to Table 4 for data information.

decrease in the probability the vendor has contracts in 2004-2005. This can be seen as support for the competition hypothesis in that market competition leads to vendor turnover even when performance does not appear to be an issue. This can be interpreted to indicate that good vendors are being replaced by, what are hoped to be, better ones.

Finally, we do not find support for the differential impact hypothesis. The interaction term, representing the product of the performance and competition variables, is not statistically distinguishable from zero $(b=0.513, p=.182)$, indicating the impact of major findings does not vary by mode of vendor selection (i.e., competitive or not). That is, poorly performing competitive contractors are no more, or less, likely to lose contracts in the next round.

The results from our model with the dependent variable accounting for the relative number of contracts held across the two time periods generally support the above findings. We see in Table 5 that, again, the "number of major findings" and "proportion of contracts competitively procured" parameter estimates are negative and statistically significant (although the $p$ value for the findings variable increases). Vendors who hold noncompetitive contracts see their ratio of contracts held diminish as their number of adverse findings increases. Likewise, vendors holding higher proportions of competitively procured contracts, but no major violations, are associated with lower ratios. We also see that, once again, the interaction term is insignificant, indicating the effect of major violations is the same regardless of whether contracts are competitive or not. The only notable difference across the models is that holding more contracts in 2003-2004 is positively associated with vendor retention in the first model and negatively associated with the ratio of contracts held in the second. So although holding more contracts makes it less likely that a vendor exits the market, it appears to make it more likely the vendor will hold fewer overall contracts in the second period (possibly because of consolidation). 


\section{Conclusion}

When we set out to search for competition in human service contracting, our initial expectation, based on the majority of findings in the extant literature, was that noncompetition would be the usual modus operandi. In our undertaking, however, we substantially broadened the concept of competition into three aspects: procurement, consolidation, and accountability. We also stretched our analysis over a 5-year span to capture trends and changes. The expansion of the conceptual and analytic scopes and the resultant findings suggest that competition in human service markets and its policy implications should be discussed within multifaceted contexts and understandings rather than in a dichotomous framework of competition versus noncompetition. Such multiplicity is observed in all three aspects of the social service contracting practices examined.

For instance, although our findings suggest that noncompetitive outsourcing is still a common practice in purchasing human services in Florida and mostly consistent with what previous studies have found in other states (e.g., Michigan-DeHoog, 1984; New YorkVan Slyke, 2003), competitiveness has been on the rise in recent years. An increase in spending through competitively procured services was particularly striking (i.e., competitively procured contracts increased as a proportion of all contract spending from $15.2 \%$ in 2000-2001 to 39.8\% in 2004-2005). A closer look at the data, however, suggests that the high level of competitive spending was mainly driven by the large CBC contracts in the family safety program, whose true competitiveness is still in need of future investigation because of their network structures and subcontracting practices.

The uniqueness of the $\mathrm{CBC}$ contracts introduces a layer of complexity as we strive to understand whether and why social service markets consolidate and what impacts and policy implications such consolidation can impose on marketized service delivery systems. For example, the fact that fewer vendors have direct contracts with the state, and that those that do tend to have larger and longer-term contracts than has traditionally been the case, signifies a potential pathway to monopolistic markets and compromised efficiency in the long run. On the other hand, the $\mathrm{CBC}$ structure allows public managers to change management (i.e., replace lead agencies) without causing severe service disruptions because the underlying network of service providers remains unchanged and thus leaves incumbent lead agencies with less leverage. This deviation from typical market structures may serve as a counterforce to the potential for monopoly outcomes.

It is interesting that although family safety contracting was transformed over the term of our study, the other large program, mental health and substance abuse services, saw very little change. Not only was there a lack of consolidation in this area, but also the use of competitive contracts did not grow nearly as much as was seen in family safety. It would appear that contractors' political clout staved off moves toward restructuring the service delivery market in this area. However, there have been some mental health and substance abuse pilot managed care programs recently, which could lead to future changes that mirror those observed in family safety (personal communication, DCF administrator, September 25, 2007). Should this occur, the CBC experience described above will take on greater relevance to a larger pool of managers as they seek to implement these transformations.

Last, we found competition to have a mixed impact regarding provider accountability. Poor performers, who secured their contracts in a noncompetitive manner and had serious 
contract violations, are less likely to maintain their contracts in the next round, as one would hope and expect. This is an interesting discovery in that the prevalence of noncompetition does not appear to routinely result in the absence of accountability-internal managerial controls seem to work. We also found evidence that higher proportions of competitively procured contracts are associated with vendor turnover, even when performance is not problematic. This is as one would expect in truly competitive markets. However, in contrast to our expectations, there was no support for the differential impact hypothesis. That is, accountability was not more stringent for contractors with greater proportions of competitively procured contracts. Vendors with competitively procured contracts were no more likely to be replaced or lose contracts in terms of the relative numbers held across the years than their noncompetitive counterparts as their number of contract violations increased.

All of these findings suggest that we need to look beyond the conventional competitionnoncompetition framework to better understand the complexity involving how public managers manage social service contracts and how they may attempt to strike a balance along the spectrum of competitive-noncompetitive means of contract management available to them to achieve effectiveness. By using a continuous rather than dichotomous view of contract management, our study contributes to expanding what Milward and Provan (2000) find in their breakthrough study of human service delivery networks. They challenge the basic premises of market theory and its applicability to human service delivery systems by suggesting that competition can be a disruptor rather than producer of program effectiveness.

We further argue and demonstrate that government utilizes a blend of competitive and noncompetitive management tools (as indicated by our findings regarding the agency's increasing use of competitive procurement, its internal managerial control across the competitively and noncompetitively procured contracts spectrum, and its increasing use of large-scale, long-term, consolidated CBC contracts) to achieve efficiency and program effectiveness. It is interesting that the most recent evaluation report on the Florida CBCs (Vargo et al., 2006) indicates that these competitively procured, but arguably noncompetitive, systems have been more successful at reaching their goals of effective child welfare service delivery than was the pre-CBC contracting scheme. Specifically what factors and network circumstances have contributed to this reported success is left to future research. The findings in this article, however, can be seen as a call for future attention to what lies beyond the competition prescription, as public managers may, on average, adopt pragmatic managerial approaches as opposed to focusing on ideological and political principles in their service delivery endeavors (Hill \& Hupe, 2002, p. 109; Warner \& Hefetz, 2004).

\section{Notes}

1. We use social services, health and human services, and human services interchangeably throughout the article. Although these terms may denote slightly different sets of services, their institutional boundaries in governmental service delivery systems are often vague, so that attempting to differentiate one from another would be impractical. Moreover, because our data set relies on one particular institutional setting (i.e., Florida Department of Children and Families $[\mathrm{DCF}]$ ) and the comprehensive sets of health, human, or social services that it provides, using these terms interchangeably suits our analytical purposes.

2. Interested readers can contact the authors for a list of the specific services examined.

3. Contract noncompliance is rated as "major" if failures could result in harm to clients, if failures could result in interruption of service, or if there is evidence of fraud or severe fiscal instability in the provider; 
"minor" if mistakes are unintentional, nonsystematic, and easily correctable such as technical errors in reporting or accounting; and "moderate" if the findings are more serious than minor but do not reach the level of a major concern (see Florida DCF, 2003b).

4. The Statewide Monitoring Reporting System (SMORES) reporting system was discontinued in FY 2004-2005. At this time, a new secretary was appointed to lead the department, which prompted a reorganization that affected the central contracting office. The new leadership chose not to continue the program.

5. Of the contracts in our analysis, $68.1 \%$ ran for 1 year or less, and $90.3 \%$ had a duration of less than 2 years. The mean length of contract over the entire time frame was 1.16 years, with a standard deviation of 0.70 $(n=6,002)$.

6. In terms of numbers, $17.6 \%$ of the contracts in the original database were dropped from the analysis because they were valued at less than $\$ 25,000$. Not surprising, because these are small contracts, those that were dropped accounted for only a small proportion of overall spending on social service contracts-less than $1 \%$ in any given year.

7. There were no notable changes over time regarding the proportion of contracts held between the sectors: For-profits consistently accounted for the smallest percentage, holding between $8.3 \%$ and $10.5 \%$ of contracts each year; other governments held the middle ground, ranging between $10.2 \%$ and $14.3 \%$; and nonprofits accounted for between $76.3 \%$ and $79.6 \%$, depending on the year. Regarding the average monetary size of contracts, once an extreme outlier was dropped, for-profits held the smallest average contracts in each year of the study. Contracts with other government entities accounted for the largest average contracts in 2000-2001, but nonprofits held the largest average contracts in each subsequent year.

8. According to the operating procedure manual of Florida DCF (2003a), an invitation to bid is defined as a "written solicitation for competitive sealed bids used when the department can specifically define the scope of work or when the department can establish precise specifications defining the actual commodity" (p. 24) and the lowest qualified bid must be accepted.

9. For example, the Florida Council for Community Mental Health is a well-known statewide association of 70 community-based mental health and substance abuse nonprofit organizations and has been highly influential in shaping behavioral health care policies in Florida. On a related note, a Florida Senate staff member has pointed out that although the legislature is aware of potential problems associated with the many exempted services, there is no current effort to curtail them, as this is a volatile issue that members generally do not want to take on.

10. Overall, competitive solicitation (i.e., a competitive method was attempted, regardless of outcome) increased by 7.7 percentage points.

11. There appears to be a reporting error in the economic self-sufficiency economic data. In FY 2000-2001, an information and referral services contract is listed as worth $\$ 26.4$ million. In subsequent years the contract ranges between $\$ 2$ million and $\$ 2.5$ million. Consultation with a DCF administrator led us to believe the discrepancy is simply the result of a "typo," but as we could not definitively identify the source of the problem, we do not discuss the financing for this program area in the text.

12. According to a report from the Florida Legislature, Office of Program Policy Analysis and Government Accountability (2006b), lead agencies are "private, community-based agencies or county governments responsible for planning, administering, and delivering client services; ensuring that services are delivered in accordance with state and federal laws; and coordinating with other local public or private agencies that offer services for clients" (p. 1).

13. An exception is the YMCA in Sarasota County, an early pilot provider that became a fully operational lead agency in 1997 (Paulson et al., 2002).

14. Some annual contracts may have extended contract periods (e.g., 18 months instead of 12 months), but we consider them as annual rather than multiyear contracts.

15. It is important to point out that we are talking only about single contract terms. It is also possible, and maybe likely, that incumbent vendors will win renewal of their contracts, which could exacerbate the situation. Unfortunately, the structure of our data does not allow us to explore this possibility.

16. SMORES also reports lesser violations that are termed "moderate" or "minor" (see Note 3). These are not used in the analysis because contract termination is likely too strong an expected sanction for such violations. As a check, we ran the model with these measures of lesser violations included, and the results were mostly identical to those reported in this article—neither variable achieved statistical significance, and the 
statistical and substantive significance of the other variables were essentially unchanged. Interested readers may obtain these results from the authors.

17. A better measure of the competitiveness of the environment would be the number of bidders for each contract, but unfortunately such information is not available. At the request of a reviewer, we also substituted the proportion of contracting dollars procured through competitive processes for the proportion of contracts measure. The results are essentially identical and are available from the authors on request.

18. Monitoring is a labor- and resource-intensive activity. As such, DCF performs a limited number of such assessments each year based most directly on contract risk level (i.e., vendors with contracts deemed "high risk" are most likely to be monitored). In FY 2004-2005, SMORES contains 205 monitoring reports, which accounts for all on-site monitoring over that time frame. There are an additional 367 contract-holding vendors that did not have on-site visits in their districts. The descriptive statistics for the monitored and nonmonitored vendors can be obtained, for purposes of comparison, by contacting the authors.

19. We are currently working to see if we can disaggregate the data down to the contract level to provide a more stringent test. This is proving an arduous task, hence our reliance on vendor-level measures in these analyses.

20. Generally, one would expect this measure to range from 0 to 1 because it would most often be the case that a vendor maintained its contracts or lost some. However, in some instances, vendors may gain additional contracts. Although this was rare, it did occur-two vendors score 1.5 and eight score 2.0 on this variable, indicating that they increased the total number of contracts held between 2003-2004 and 2004-2005 by 50\% and $100 \%$, respectively. Those that score 1.5 increased their holdings from two contracts to three and all those scoring 2.0 increased from one to two.

\section{References}

Bardach, E., \& Lesser, C. (1996). Accountability in human services collaboratives: For what? And to whom? Journal of Public Administration Research and Theory, 6(2), 197-224.

Blasi, G. J. (2002). Government contracting and performance measurement in human services. International Journal of Public Administration, 25(4), 519-538.

Brown, T. L., \& Potoski, M. (2003). Transaction costs and institutional explanations for government service production decisions. Journal of Public Administration Research and Theory, 13(4), 441-468.

Courtney, M. E. (2000). Managed care and child welfare services: What are the issues? Children and Youth Services Review, 22(2), 87-91.

DeHoog, R. H. (1984). Contracting out for human services: Economic, political, and organizational perspectives. Albany: State University of New York Press.

DeHoog, R. H. (1990). Competition, negotiation, or cooperation: Three models for service contracting. Administration \& Society, 22, 317-340.

Dicke, L. A. (2002). Insuring accountability in human services contracting: Can stewardship theory fill the bill? The American Review of Public Administration, 32, 455-470.

Dicke, L. A., \& Ott, J. S. (1999). Public agency accountability in human services contracting. Public Productivity and Management Review, 22(4), 502-516.

Donahue, J. D. (1989). The privatization decision: Public ends, private means. New York: Basic Books.

Embry, R. A., Buddenhagen, P., \& Bolles, S. (2000). Managed care and child welfare: Challenges to implementation. Children and Youth Services Review, 22(2), 93-116.

Falconer, M. K., Cash, S., \& Ryan, S. (2001). Evaluation of community-based care in foster care and related services in Florida. Retrieved June 15, 2007, from http://www.dcf.state.fl.us/publications/docs/cover.pdf

Ferris, J., \& Graddy, E. (1986). Contracting out: For what? With whom? Public Administration Review, $46,343-354$.

Field, T. (1996). Managed care and child welfare: Will it work? Public Welfare, 54(3), 4-10.

Florida Department of Children and Families. (2003a). Contract management system for contractual services (CFOP 75-2). Retrieved June 15, 2007, from http://www.def.state.fl.us/publications/policies/075-2.pdf

Florida Department of Children and Families. (2003b). Contract monitoring. (CFOP 75-8) Retrieved June 15, 2007, from http://www.dcf.state.fl.us/publications/policies/075-8.pdf 
Florida Department of Children and Families. (2005). Purchasing policy and procedures (CFOP 75-1). Retrieved June 15, 2007, from http://www.dcf.state.fl.us/publications/policies/075-1.pdf

Florida Legislature, Office of Program Policy Analysis and Government Accountability. (2004). DCF improves readiness assessment process: However, additional changes are needed (Report 04-65). Retrieved June 15, 2007, from http://www.oppaga.state.fl.us/reports/pdf/0465rpt.pdf

Florida Legislature, Office of Program Policy Analysis and Government Accountability. (2006a). Additional improvements are needed as DCF redesigns its lead agency oversight system (Report 06-05). Retrieved June 15, 2007, from http://www.oppaga.state.fl.us/reports/pdf/0605rpt.pdf

Florida Legislature, Office of Program Policy Analysis and Government Accountability. (2006b). The Department of Children and Families has taken steps to address 2005 contracting law (Report 06-16). Retrieved June 15, 2007, from http://www.oppaga.state.fl.us/reports/health/r06-16s.html

Greene, J. D. (1996). Cities and privatization: Examining the effect of fiscal stress, location, and wealth in medium-sized cities. Policy Studies Journal, 24(1), 135-144.

Greene, J. D. (2002). Cities and privatization: Prospects for the new century. Upper Saddle River, NJ: Prentice Hall.

Hill, M., \& Hupe, P. (2002). Implementing public policy. London: Sage.

Kearns, K. P. (1994). The strategic management of accountability in nonprofit organizations: An analytical framework. Public Administration Review, 54(2), 186-192.

Keating, E. K., \& Frumkin, P. (2003). Reengineering nonprofit financial accountability: Toward a more reliable foundation for regulation. Public Administration Review, 63(1), 3-15.

Kettl, D. (1993). Sharing power: Public governance and private market. Washington, DC: Brookings Institution.

Kramer, R. M. (1994). Voluntary agencies and the contract culture: Dream or nightmare. Social Service Review, 68(1), 33-60.

Kramer, R. M., \& Grossman, B. (1987). Contracting for social services: Process management and resource dependencies. Social Service Review, 61, 33-55.

Lamothe, M. (2004). Issues of contract implementation and management: The case of performance contracting in Florida human services. International Review of Public Administration, 8(2), 59-75.

McCullough, C., \& Schmitt, B. (2000). Managed care and privatization: Results of a national survey. Children and Youth Services Review, 22(2), 117-130.

McCullough, C., \& Schmitt, B. (2003). Management, finance, and contracting survey final report. Systems Integration Management Institute. Washington, DC: Child Welfare League of America.

Milward, H. B., \& Provan, K. G. (2000). Governing the hollow state. Journal of Public Administration Research and Theory, 10(2), 359-379.

Ostrom, V., \& Ostrom, E. (1971). Public choice: A different approach to public administration. Public Administration Review, 31, 203-216.

Paulson, R. I., Armstrong, M., Brown, E., Jordan, N., Kershaw, M. A., Vargo, A., et al. (2002). Evaluation of the Florida Department of Children and Families Community-Based Care initiative in Manatee, Sarasota, Pinellas, and Pasco Counties: Final report on fiscal year 2001-2002. Tampa: University of South Florida, Louis de la Parte Florida Mental Health Institute.

Romzek, B. S., \& Dubnick, M. J. (1994). Issues of accountability in flexible personnel systems. In P. W. Ingraham \& B. S. Romzek (Eds.), New paradigm for government: Issues for the changing public service (pp. 263-294). San Francisco: Jossey-Bass.

Romzek, B. S., \& Johnston, J. M. (2005). State social services contracting: Exploring the determinants of effective contract accountability. Public Administration Review, 65, 436-449.

Salamon, L. M. (1987). Partners and public service: The scope and theory of government-nonprofit relations. In W. W. Powell (Ed.), The nonprofit sector: A research handbook (pp. 99-117). New Haven, CT: Yale University Press.

Savas, E. S. (2000). Privatization and public-private partnerships. New York: Chatham House.

Savas, E. S. (2002). Competition and choice in New York City social services. Public Administration Review, 62(1), 82-91.

Sclar, E. D. (2000). You don't always get what you pay for: The economics of privatization. Ithaca, NY: Cornell University Press.

Smith, S. R., \& Lipsky, M. (1993). Nonprofit for hire: The welfare state in the age of contracting. Cambridge, MA: Harvard University Press. 
Stone, M., Bigelow, B., \& Crittenden, W. (1999). Research on strategic management in nonprofit organizations: Synthesis, analysis, and future directions. Administration \& Society, 3, 378-423.

Torrey, F. E. (1997). Out of the shadows: Confronting America's mental illness crisis. New York: John Wiley. Tullock, G. (1965). The politics of bureaucracy. Washington, DC: Public Affairs Press.

University of Florida. (2005). Florida statistical abstracts. Gainesville: University of Florida, Bureau of Economic and Business Research, Warren College of Business.

Van Slyke, D. M. (2003). The mythology of privatization in contracting for social services. Public Administration Review, 63, 296-315.

Vargo, A., Armstrong, M., Jordan, N., Kershaw, M. A., Pedraza, J., \& Yampolskaya, S. (2006). Evaluation of the Department of Children and Families Community-Based Care Initiative, fiscal year 2004-2005. Retrieved June 15, 2007, from http://www.dcf.state.fl.us/publications/docs/CBC_Report_feb06_final.pdf

Warner, M., \& Hefetz, A. (2004). Pragmatism over politics: Alternative service delivery in local government, 1992-2002. Municipal year book 2004. Washington, DC: International City/County Management Association.

Williamson, O. E. (1985). The economic institutions of capitalism: Firms, markets, relational contracting. New York: Free Press.

Meeyoung Lamothe is an assistant professor at the University of Oklahoma. Recent research interests include local alternative service delivery arrangements, social service contracting, and nonprofit management. Recent and upcoming publications may be found in International Journal of Public Administration, International Review of Public Administration, and Urban Affairs Review.

Scott Lamothe is an assistant professor in the department of political science at the University of Oklahoma. His current research focuses on state policy innovation and alternative delivery arrangements for publicly provided services. Recent and upcoming publications may be found in International Journal of Public Administration, State and Local Government Review, and Urban Affairs Review. 